\title{
Исследование параметров внутренней картины болезни пациентов ревматологического профиля
}

\author{
Владимир М. Ялтонский, Илья Н. Абросимов", Тамара Д. Андрушкевич, Елизавета М. Шашурина \\ Московский государственный медико-стоматологический университет им. А. И. Евдокимова, г. Москва, \\ Российская Федерация \\ *E-mail: i.abrosimov@bk.ru \\ ORCID ID: https://orcid.org/0000-0003-3337-0123, https://orcid.org/0000-0003-1981-4170, https:// \\ orcid.org/0000-0002-7450-9083, https://orcid.org/0000-0001-6999-8612
}

\begin{abstract}
Аннотация
Ввеление. Внутренняя картина болезни (ВКБ) пациента рассматривается и в качестве олного из результатов процесса его алаптации к заболеванию, и в качестве инструмента саморегуляции ^ичности в условиях болезни. Аанный психологический конструкт активно изучается современной кАинической психологией, что Аополняет имеющиеся на сегодняшний Аень Аанные, полученные в холе определения психологических фракторов ^ечебного процесса. Применение многоуровневой модели ВКБ, фрокусирующей свое внимание на восприятии болезни и совлалании с ней, осуществ^яется впервые на выборке пациентов ревматологического профиияя.
\end{abstract}

Методы. Было обследовано 80 пациентов с ревматическими болезнями в возрасте от 18 АО 52 ^ет: 40 пациентов с ревматоиАным артритом (РА), 40 пациентов с системной красной волчанкой (СКВ). Применялся пакет психодиагностических метоАик, позволяющий описать структуру и солержание различных уровней внутренней картины болезни: опросник выраженности психопатологической симптоматики (SCL 90-r); краткий опросник восприятия бо^езни; методика А^я психологической Аиагностики способов совлаАания со стрессовыми и проблемными Аля Аичности ситуациями.

Результаты. В группах сравнения были получены статистически значимые различия: по шкалам восприятия болезни - «понимание болезни», «течение болезни», «Контроль болезни», «Контроль ^ечения»; по шкалам копинг-поведения - «поиск социальной поАлержки», «принятие ответственности»; по шкалам «соматизация», «Аепрессивносты), «тревога». Установленные корреляции указывают на соотношение межАу собой параметров различных уровней внутренней картины болезни пациентов в обеих группах.

ОбсужАение результатов. Параметры внутренней картины болезни пациентов с системной красной волчанкой говорят о стремлении пациентов осознать и преололеть выраженную неопределенность и непредсказуемость имеющегося у них заболевания, олнако это не снижает их эмоциональной вовлеченности в проблему. Внутреннюю картину болезни пациентов с ревматоилным артритом характеризуют худшее понимание и контроль заболевания, а также сорокусированные на эмоциях копинг-стратегии, направленные на Аистанцирование от тревожных переживаний, связанных с болезнью. 
ЯЛТОНСКИЙ В. М., АБРОСИМОВ И. Н., АНДРУШКЕВИЧ Т. Д., ШАШУРИНА Е. М.

ИССЛЕДОВАНИЕ ПАРАМЕТРОВ ВНУТРЕННЕЙ КАРТИНЫ БОЛЕЗНИ...

РОССИЙСКИЙ пСИХОЛОГИЧЕСКИЙ ЖУРНАЛ, 2020, Т. 17, № 1, 15-26. doi: 10.21702/rpj.2020.1.2

МЕДИЦИНСКАЯ ПСИХОЛОГИЯ

\section{КАючевые слова}

ревматические болезни, ревматоилный артрит, системная красная волчанка, внутренняя картина болезни, восприятие болезни, совлалающее поведение, копинг, аАаптация личности, саморегуляция, психология пациента

\section{Основные положения}

จ ревматические болезни являются универсальной моделью Аля психологического исслеАОвания адаптации к хроническому заболеванию;

> в обеих группах пациентов отмечаются схожие показатели чувственного уровня ВКБ, что обусловлено спецификой Аифффузного, мультисистемного течения ревматических заболеваний; показатели эмоционального уровня ВКБ отражают выраженную готовность тревожно-фробического реагирования пациентов С CКВ;

> соотношение показателей когнитивного и поведенческого уровней ВКБ указывает: субъективное восприятие пациентами СКВ сорокусировано на понимании своего заболевания, его течения и контроля; совладание пациентов с РА характеризуется игнорированием копинг-ресурсов и низким Контролем наА болезнью.

\section{Для цитирования}

Ялтонский, В. М., Абросимов, И. Н., Андрушкевич, Т. Д. и Шашурина, Е. М. (2020). Исследование параметров внутренней картины болезни пациентов ревматологического профиля. Российский психологический журнал, 17(1), 15-26. doi: 10.21702/rpj.2020.1.2

Дата получения рукописи: 30.01 .2020 Дата окончания рецензирования: 07.03.2020 Дата принятия к публикации: 11.03 .2020

\section{Введение}

Ревматические заболевания представляют особый интерес для современной клинической психологии, являясь как уже традиционным, так и всё еще актуальным предметом ее исследований. Во-первых, это обусловлено смешанной и не до конца изученной этиологией данной нозологической группы, не исключающей роль психологических факторов в возникновении и обострении коллагенозов (Воробьева, Асеева, Соловьев, Койлубаева и Глухова, 2019). Так, например, уже традиционным стало рассмотрение ревматоидного артрита наряду с нейродермитом, язвой ДПК и другими заболеваниями в рамках так называемой “святой ("чикагской") семерки» психосоматических болезней (Алпысова и Суббота, 2017). С другой стороны, ревматические заболевания, в силу своей полиорганной и диффузной симптоматики, зачастую не имеющей яркой манифестации и сопровождающей заболевшего человека в качестве болезненных и сковывающих телесных ощущений в течение долгого периода жизни, являются наглядной моделью хронического соматического заболевания, подразумевающей особый тип адаптации личности к болезни и ассоциированным с ней ограничениям (в т. ч. социальным и психологическим) функционирования (Грехов и др., 2009).

Всё чаще в литературе процесс адаптации к болезни соотносится с такими психологическими и интегративными конструктами, как внутренняя картина болезни (Вассерман, Чугунов и Щелкова, 2019), комплаентность (Абросимов и Ялтонский, 2018) и качество жизни (Месникова 
ЯЛТОНСКИЙ В. М., АБРОСИМОВ И. Н., АНДРУШКЕВИЧ Т. Д., ШАШУРИНА Е. М.

ИССЛЕДОВАНИЕ ПАРАМЕТРОВ ВНУТРЕННЕЙ КАРТИНЫ БОЛЕЗНИ...

РосСИЙСКИЙ пСИХОЛОГИЧЕСКИЙ ЖУРнАл, 2020, Т. 17, № 1, 15-26. doi: 10.21702/rpj.2020.1.2

МЕДИЦИНСКАЯ ПСИХОЛОГИЯ

и Сенюта, 2016). Изучение этих клинико-психологических показателей на выборке пациентов ревматологического профиля является одной из актуальных задач, решение которой позволит дополнить имеющиеся на сегодняшний день данные психологических исследований, посвященных описанию депрессивных расстройств и других коморбидных психопатологических нарушений аффективного спектра (Марченко, Серавина, Ковалевская, Вельтищев и Лисицына, 2009). И, наконец, несмотря на успехи и достижения современной высокотехнологичной медицины (Соловьев, Меснянкина и Асеева, 2019), некоторые ревматические болезни остаются настолько широко распространенными среди общей популяции, что это придает им характер «обыденных явлений» (Березина, 2011). При этом их мало локализованная и неявная на первых этапах заболевания симптоматика не заставляет обращать на себя должного внимания. Всё это обуславливает тот факт, что мониторинг, своевременное и адекватное лечение ревматических болезней остаются недостаточными среди населения (Хамитов, Хисметова, Горемыкина, Танышева и Котляр, 2019), а также подчеркивает важность разработок в области профилактики данной проблемы (Бегун и Борщук, 2013).

Одними из ключевых клинико-психологических конструктов, рассматриваемых современной клинической психологией в качестве обуславливающих характер и результаты процесса саморегуляции личности в условиях заболевания, являются восприятие имеющейся болезни (Ялтонский и Абросимов, 2011) и совладающее с ней (копинг-) поведение (Кудряшова, Сарайкин и Иванов, 2017). В отечественной исследовательской традиции данные показатели, наряду с телесным и эмоциональным опытом, чаще изучаются в рамках внутренней картины болезни, выступающей в роли органа саморегуляции личности в условиях заболевания (Рассказова, 2012). Традиционно в структуре внутренней картины болезни (ВКБ) принято выделять следующие уровни: чувственный - интрацептивный опыт, связанный с болезнью и ее лечением; эмоциональный - аффективное содержание связанных с болезнью переживаний; интеллектуальный - когнитивные репрезентации болезни, представления о ее причинах и последствиях; мотивационный - те действия, которые предпринимает индивид для преодоления болезни или адаптации к ней. На сегодняшний день имеется недостаточное количество интегративных психологических исследований с участием пациентов ревматологического профиля, посвященных внутренней картине болезни и фокусирующих свое внимание на роли восприятия болезни и совладания с ней, что подчеркивает актуальность настоящей работы.

Целью исследования являлось изучение особенностей многоуровневой структуры внутренней картины болезни пациентов с ревматоидным артритом и системной красной волчанкой.

Задачи исследования: 1. Оценка показателей чувственного и эмоционального уровней ВКБ. 2. Описание структурных особенностей когнитивного и мотивационного уровней ВКБ. 3. Анализ установленных связей между изучаемыми параметрами ВКБ.

\section{Методы}

В исследовании приняли участие 80 пациентов ФГБНУ «Научно-исследовательский институт ревматологии им. В. А. Насоновой». Группами сравнения являлись: группа РА - 40 пациентов с ревматоидным артритом (среди них 3 мужчин) и группа СКВ - 40 пациентов с системной красной волчанкой (среди них 5 мужчин). Средний возраст участников исследования составил $34,00 \pm 17,46$ лет.

В ходе исследования применялся пакет из следующих психодиагностических методик: для оценки показателей чувственного и эмоционального уровней ВКБ использовались 
ЯЛТОНСКИЙ В. М., АБРОСИМОВ И. Н., АНДРУШКЕВИЧ Т. Д., ШАШУРИНА Е. М.

ИССЛЕДОВАНИЕ ПАРАМЕТРОВ ВНУТРЕННЕЙ КАРТИНЫ БОЛЕЗНИ...

РОсСИЙСКИЙ ПСИХОЛОГИЧЕСКИЙ ЖУРНАЛ, 2020, Т. 17, № 1, 15-26. doi: 10.21702/rpj.2020.1.2

МЕДИЦИНСКАЯ ПСИХОЛОГИЯ

шкалы «соматизация», «тревожность», «депрессивность» опросника выраженности психопатологической симптоматики SCL 90-r (Тарабрина, 2001); для описания структурных особенностей когнитивного уровня - краткий опросник восприятия болезни (Ялтонский, Московченко, Сирота и Ялтонская, 2017); для описания структурных особенностей мотивационного уровня ВКБ - методика для психологической диагностики способов совладания со стрессовыми и проблемными для личности ситуациями (Вассерман и др., 2019). Также применялся пакет программ статистической обработки данных SPSS (v.20, 2011): сравнительный анализ с применением критерия U Манна-Уитни и корреляционный анализ по критерию Спирмена.

\section{Результаты}

В ходе исследования показателей чувственного и эмоционального уровней ВКБ было установлено, что статистически значимых отличий по шкале «соматизация» между сравниваемыми группами пациентов не было обнаружено. При этом показатели по данной шкале в обеих группах превышали нормативные показатели (СКВ - 1,67 $\pm 0,71$; PA - 1,50 \pm 0,58; норма - 0,69 \pm 0,65), приведенные авторами адаптации методики, что указывает на высокую вероятность наличия у данных пациентов дистресса, связанного с переживанием внутреннего телесного опыта болезни и его лечения. Показатели шкалы «депрессия» не превышают нормативный интервал в обеих группах (СКВ - 1,23 \pm 0,61; PA - 1,10 $\pm 0,68 ;$ норма - 0,68 $\pm 0,59)$. Это говорит об умеренной выраженности депрессивных переживаний и их когнитивных и соматических коррелятов. Статистически значимые различия между двумя группами были получены по шкале «тревожность» $(p=0,001)$. Данный показатель также превышал нормативные данные в группе пациентов с системной красной волчанкой (СКВ - 1,30 $\pm 0,80 ;$ норма - 0,58 $\pm 0,53)$, что указывает на наличие у них не только манифестированной тревоги, но и когнитивных компонентов тревоги, таких как переживание опасности на фоне неопределенности. Более подробно результаты данного этапа исследования представлены на рисунке 1.

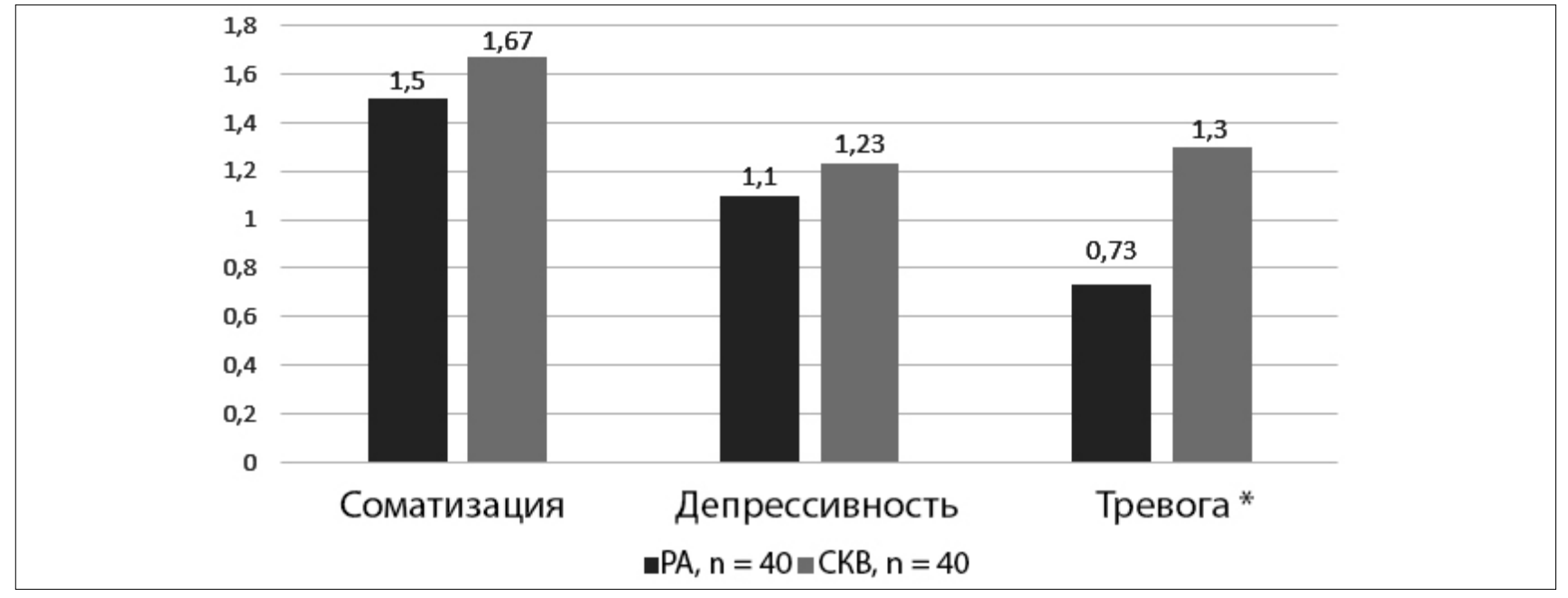

Рисунок 1. Результаты сравнительного анализа показателей чувственного и эмоционального уровней ВКБ в сравниваемых группах по критерию U Манна-Уитни, $\mathrm{n}=80$

Условные обозначения: * - шкалы, по которым были обнаружены статистически значимые различия при р $\leq 0,05$. 
ЯЛТОНСКИЙ В. М., АБРОСИМОВ И. Н., АНДРУШКЕВИЧ Т. Д., ШАШУРИНА Е. М.

ИССЛЕДОВАНИЕ ПАРАМЕТРОВ ВНУТРЕННЕЙ КАРТИНЫ БОЛЕЗНИ...

РосСИЙСКИЙ пСИХОЛОГИЧЕСКИЙ ЖУРнАл, 2020, Т. 17, № 1, 15-26. doi: 10.21702/rpj.2020.1.2

МЕДИЦИНСКАЯ ПСИХОЛОГИЯ

Исследование показателей когнитивного уровня ВКБ показало, что в сравниваемых нозологических группах присутствует структурная специфика восприятия имеющегося заболевания. Так, если пациенты репрезентируют ревматоидный артрит как заботящее их заболевание с длительным течением и хорошо узнаваемой симптоматикой, то, в свою очередь, пациенты с системной красной волчанкой также озабочены заболеванием и его длительностью, но при этом лучше его понимают. При этом статистически значимые различия между сравниваемыми группами обнаружены по шкалам «течение», «контроль болезни», «контроль лечения». Более подробно результаты данного этапа представлены в таблице 1.

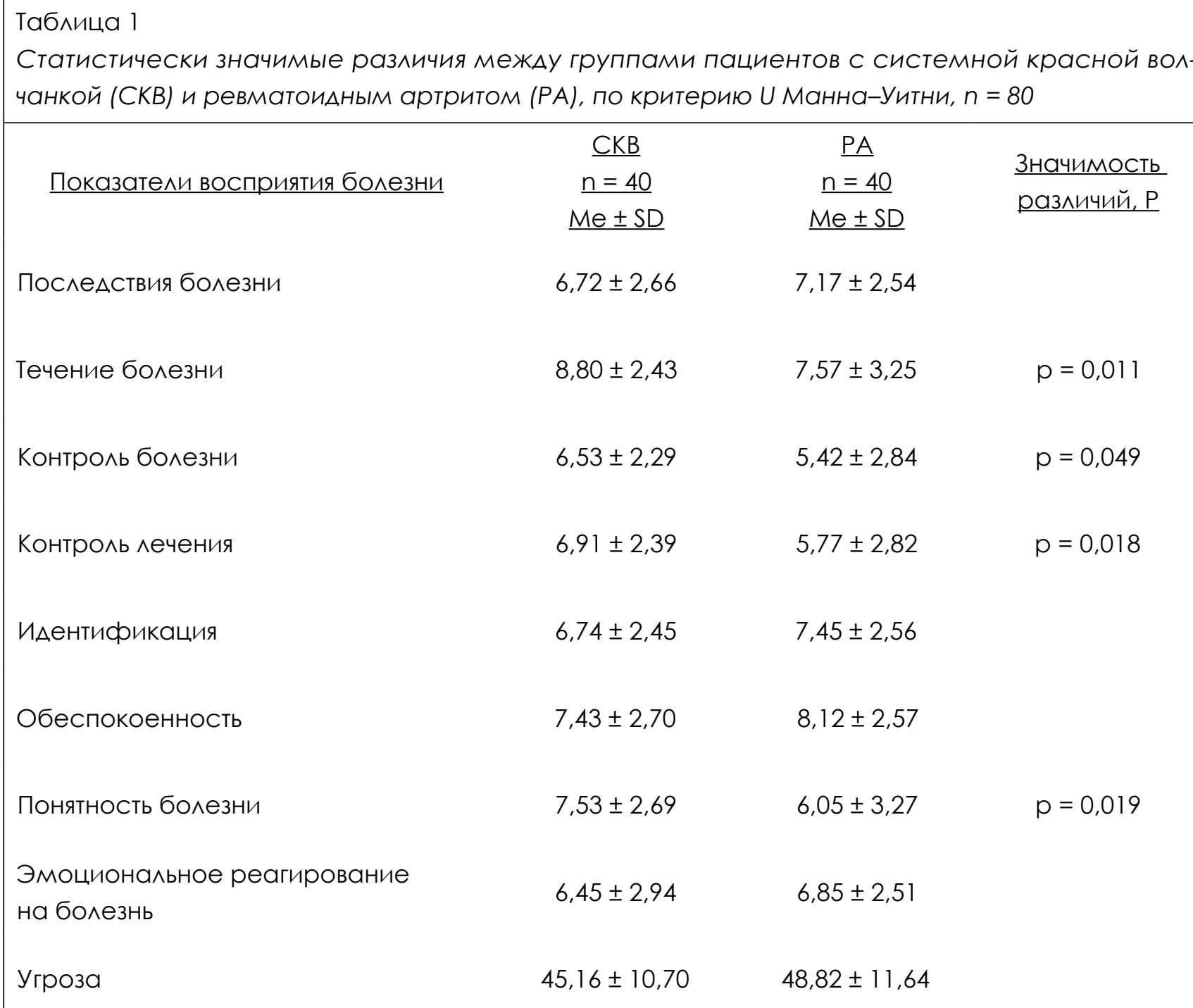

Среди показателей мотивационного уровня ВКБ пациентов обеих групп на первый план выступали копинг-стратегии «бегство - избегание» и «поиск социальной поддержки». Однако 
ЯЛТОНСКИЙ В. М., АБРОСИМОВ И. Н., АНДРУШКЕВИЧ Т. Д., ШАШУРИНА Е. М.

ИССЛЕДОВАНИЕ ПАРАМЕТРОВ ВНУТРЕННЕЙ КАРТИНЫ БОЛЕЗНИ...

РОсСиЙСКИЙ пСИХОЛОГИЧЕСКИЙ ЖХУРнАл, 2020, Т. 17, № 1, 15-26. doi: 10.21702/rpj.2020.1.2

МЕДИЦИНСКАЯ ПСИХОЛОГИЯ

если в группе РА также ведущей является стратегия «дистанцирование», то в группе СКВ - «планирование решения проблем». Важно отметить также, что все показатели копинг-поведения в обеих группах не превышали нормативные данные, приведенные авторами методики, что указывает на их умеренное применение, которое в целом повышает адаптивное функционирование (Вассерман и др., 2019). Статистически значимые различия двух групп были получены также по шкалам «поиск социальной поддержки» (CKB - 51,44 \pm 9,49; PA - 48,20 \pm 8,47; $p=0$ 0,49) и «принятие ответственности» (СКВ - 48,90 $\pm 10,18 ; \mathrm{PA}-44,25 \pm 12,61 ; p=0,46)$ с преобладанием данных показателей в группе СКВ. Более подробно результаты данного этапа исследования представлены на рисунке 2.

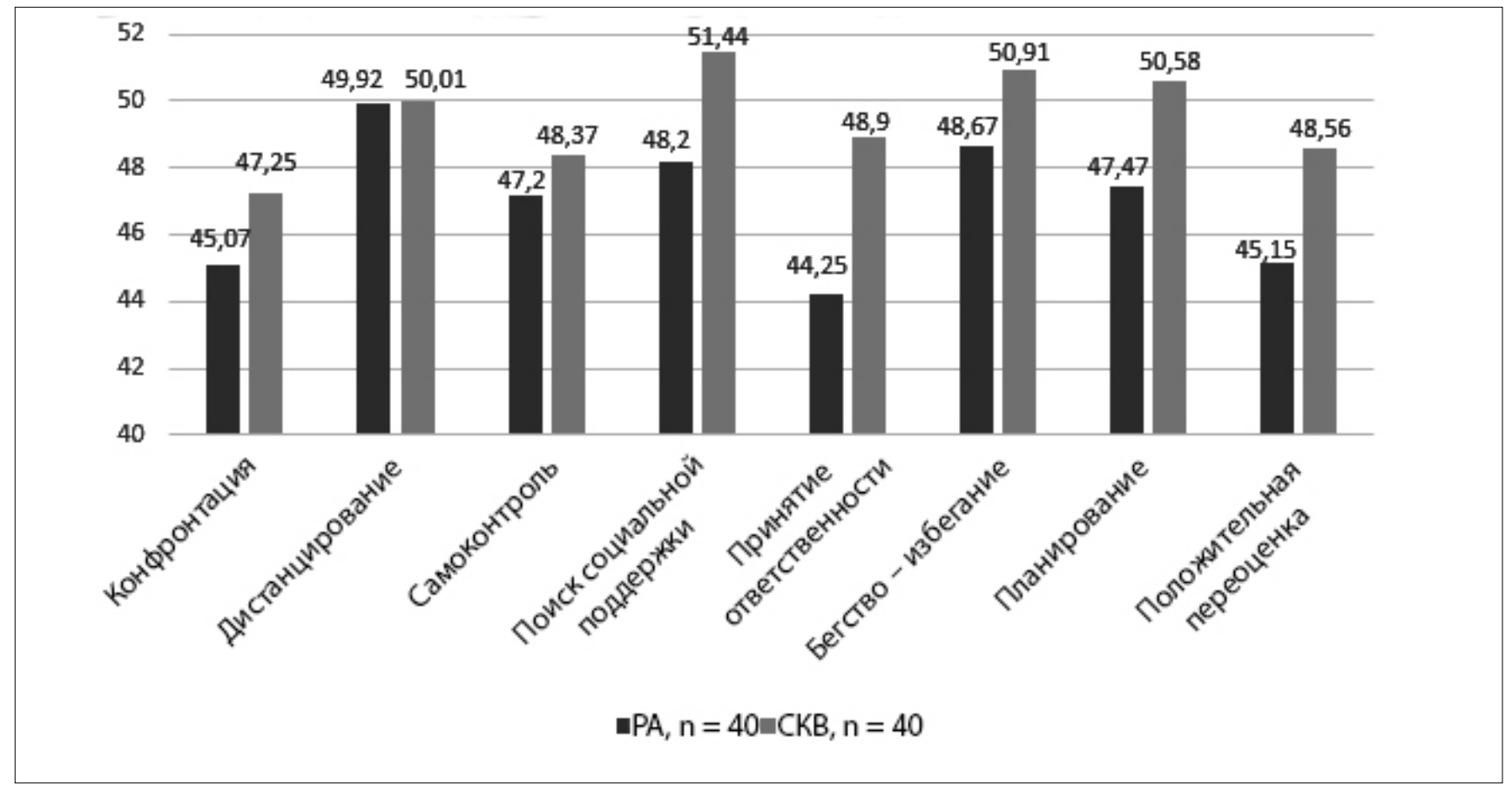

Рисунок 2. Результаты сравнительного анализа показателей совлалающего повеАения в сравниваемых полгруппах по критерию U Манна - Уитни, $\mathrm{n}=80$

Условные обозначения: *- шкалы, по которым были обнаружены статистически значимые различия при р $\leq 0,05$.

В ходе проведенного корреляционного анализа в двух группах сравнения были установлены связи между изучаемыми параметрами внутренней картины болезни. В группе пациентов с ревматоидным артритом были установлены множественные положительные корреляции между показателями восприятия болезни и показателями чувственного, эмоционального и мотивационного уровней ВКБ. Меньшее количество прямых и обратных связей между исследуемыми параметрами было установлено в группе пациентов с системной красной волчанкой. Их встречаемость носит единичный характер и указывает, скорее, на имеющуюся тенденцию соотношения восприятия болезни с эмоциональным уровнем ВКБ. Более подробно результаты корреляционного анализа представлены в таблице 2. 
ЯЛТОНСКИЙ В. М., АБРОСИМОВ И. Н., АНДРУШКЕВИЧ Т. Д., ШАШУРИНА Е. М.

ИССЛЕДОВАНИЕ ПАРАМЕТРОВ ВНУТРЕННЕЙ КАРТИНЫ БОЛЕЗНИ...

РосСИЙСКИЙ пСИХОЛОГИЧЕСКИЙ ЖУРнАл, 2020, Т. 17, № 1, 15-26. doi: 10.21702/rpj.2020.1.2

МЕДИЦИНСКАЯ ПСИХОЛОГИЯ

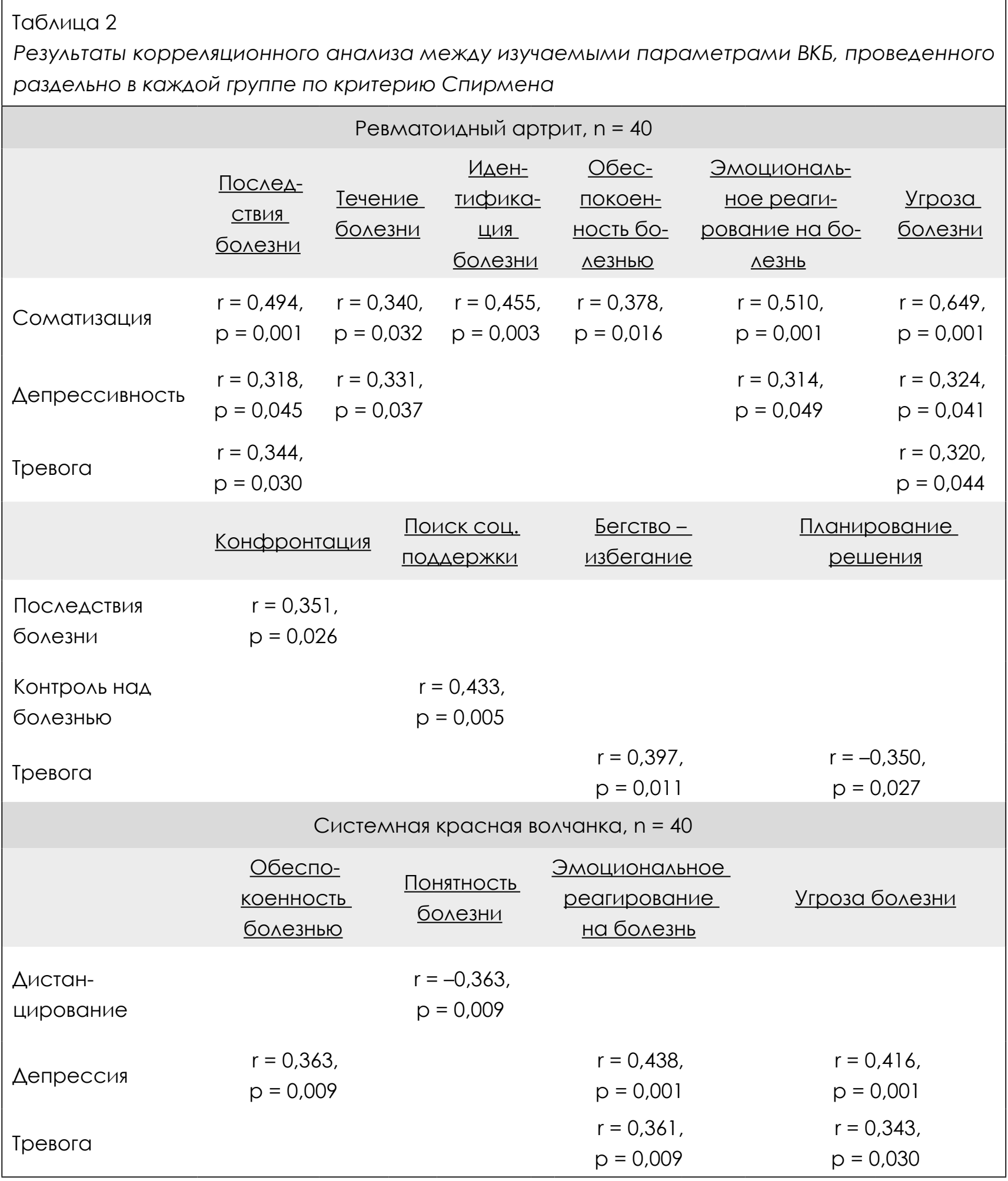


ЯЛТОНСКИЙ В. М., АБРОСИМОВ И. Н., АНДРУШКЕВИЧ Т. Д., ШАШУРИНА Е. М.

ИССЛЕДОВАНИЕ ПАРАМЕТРОВ ВНУТРЕННЕЙ КАРТИНЫ БОЛЕЗНИ...

РОССИЙСКИЙ ПСИХОЛОГИЧЕСКИЙ ЖУРНАЛ, 2020, Т. 17, № 1, 15-26. doi: 10.21702/rpj.2020.1.2

МЕДИЦИНСКАЯ ПСИХОЛОГИЯ

\section{Обсуждение результатов}

Полученные результаты настоящего исследования структурных особенностей ВКБ пациентов ревматологического профиля дополняют имеющиеся классические данные, опираясь на многоуровневую модель данного психологического конструкта. Так, важным представляется описание показателей чувственного уровня ВКБ, недостаточно освещенных в психологической литературе. Как в группе пациентов с ревматоидным артритом, так и в группе пациентов с системной красной волчанкой отмечается наличие дистресса на фоне имеющегося телесного опыта или чувственной ткани болезни (Цветкова, 2012). Оба заболевания отличаются непредсказуемым нелинейным течением с периодами ремиссий и рецидивов, а также непонятными или незаметными на начальном этапе телесными проявлениями (Кулик, Барзилович и Минченко, 2012). Это повышает уровень неопределенности личности в условиях болезни (Лифинцева, Деркач и Штолде, 2018) и отражается на качестве жизни и других показателях адаптации к болезни (Ялтонский и Абросимов, 2014). Отсутствие значимых различий указывает на схожесть диффузного внутреннего телесного (в т. ч. проприоцептивного) опыта пациентов обеих нозологических групп, несмотря на имеющуюся клиническую специфику данных заболеваний. Однако сформированность и дифференциация именно чувственного уровня рассматривается в качестве одного из системообразующих факторов согласованности ВКБ (Василенко и Мангушев, 2018). Это, в свою очередь, обуславливает важность учета данного параметра в психокоррекционной работе с пациентами ревматологического профиля.

Традиционно ассоциирующиеся с дисфункционально высокими показателями нарушений аффективного спектра (Лисицина и др., 2018), пациенты ревматологического профиля в данном исследовании демонстрируют умеренные показатели депрессивных переживаний и контрастную картину тревожности на эмоциональном уровне ВКБ в сравниваемых группах. Пациенты с системной красной волчанкой имеют большую готовность тревожного реагирования на возможные и непредсказуемые опасности имеющегося у них заболевания, в сравнении с пациентами с ревматоидным артритом. Согласно биопсихосоциальной модели, часто применяемой в современной клинической психологии, данные результаты могут быть обусловлены различными, в том числе и социокультурными, факторами (Незнанов, Коцюбинский и Мазо, 2018). Как уже говорилось выше, важную роль в эмоциональном реагировании на болезнь могут играть «повседневная обыденность» ревматоидного артрита, а также высокая «неопределенность» системной красной волчанки, непонятность и несформированность ее образа для самих пациентов и их окружения (Воробьева и Асеева, 2017).

Полученные данные соотносятся с результатами исследований Nowicka-Sauer et al. (2018), где было показано: чем меньше пациент с системной красной волчанкой знает о своем заболевании, тем с большей вероятностью возрастает уровень тревоги, депрессии, а также качество сна и восприятие боли. Также было установлено, что большинство пациентов среднего возраста имеют негативные представления о своем заболевании, что также увеличивает вероятность повышения уровня тревоги, восприятия боли (Ulus et al., 2017).

Однако результаты исследования восприятия болезни как показателя когнитивного уровня ВКБ вступают в некоторое противоречие с вышепредложенным тезисом. Пациенты с системной красной волчанкой отличаются от пациентов с ревматоидным артритом лучшим пониманием своей болезни и ее длительного течения, а также субъективным восприятием более высокого контроля над ней. При этом, как уже здесь отмечалось, СКВ - это трудно поддающееся коррекции хроническое заболевание с неравномерным течением в виде 
ЯЛТОНСКИЙ В. М., АБРОСИМОВ И. Н., АНДРУШКЕВИЧ Т. Д., ШАШУРИНА Е. М.

ИССЛЕДОВАНИЕ ПАРАМЕТРОВ ВНУТРЕННЕЙ КАРТИНЫ БОЛЕЗНИ...

РосСИЙСКИЙ пСИХОЛОГИЧЕСКИЙ ЖУРнАл, 2020, Т. 17, № 1, 15-26. doi: 10.21702/rpj.2020.1.2

МЕДИЦИНСКАЯ ПСИХОЛОГИЯ

ремиссий и рецидивов (Yen \& Singh, 2018). Опыт других исследований, посвященных восприятию хронических системных заболеваний (Karademas et al., 2008), позволяет предположить, что возможной причиной этого может служить разница между субъективным восприятием и объективной реализацией некоторых параметров ВКБ. Так, рецидивирующее заболевание, редко встречаемое в популяции и вносящее высокий уровень неопределенности в повседневную жизнь (каким является СКВ), требует от пациента прикладывать больше усилий, чтобы понять и контролировать его (Pakhale et al., 2015). Но, при этом, попытки понять механизмы течения своего заболевания и его обострений приводят к осознанию его сложности и тяжести, а попытки контролировать болезнь, хотя и являются инструментом саморегуляции, но остаются ограниченными и с недолгосрочным эффектом. Этими факторами могут быть объяснены высокие показатели тревоги, описанные выше.

Отрицательная корреляционная связь между копингом «дистанцирование» и пониманием болезни в группе пациентов с СКВ частично подтверждает данное предположение и указывает на тенденцию их к погружению в эмоциональные переживания, связанные с болезнью на фоне лучшего понимания ее механизмов.

Исследование копинг-поведения в условиях болезни отражает его более эффективные показатели в группе с системной красной волчанкой на фоне пациентов с ревматоидным артритом. Обе группы используют целый спектр различных умеренно выраженных стратегий совладания, что рассматривается современными авторами как адаптивная гибкость защитно-совладающего поведения (Mc Hugh, Mc Feeters, Boyda, \& O'Neill, 2016). Однако в группе PA менее выражены стратегии поиска социальной поддержки и принятия ответственности, что в условиях болезни может снижать эффективность попыток адаптации. Ведущими негативными феноменами на этом фоне может выступать отсутствие мотивации, как внешней, так и внутренней, для соблюдения должных предписаний, что отражается на снижении приверженности лечению (Brijs, Arat, Westhovens, Lenaerts, \& De Langhe, 2019). Также высокой остается готовность к избегающим и конфронтативным формам реагирования на стресс в данной группе.

Установленные корреляции в группе пациентов с ревматоидным артритом указывают на тенденцию к использованию внешних ресурсов для контроля над заболеванием, а также к применению избегающего стиля поведения для снижения уровня тревоги, что может приводить к снижению адаптации личности в условиях болезни (Li, He, Wang, \& Wang, 2019).

Полученные результаты дополняют данные, полученные в исследовании Ахмедовой и Щелковой (2008), где было показано, что на фоне пациентов с остро протекающим и объективно угрожающим жизни онкологическим заболеванием, больные ревматоидным артритом применяют менее эффективные стратегии совладания. Однако фокус меняется при сравнении показателей данной нозологической группы с другими ревматическими болезнями. Этот факт еще раз подчеркивает важность ведения дискурса об относительности адаптивных копингов и учете комплексного подхода к их изучению.

В целом внутренняя картина болезни пациентов ревматологического профиля остается актуальным и значимым предметом для психологических исследований, поскольку изучение ее параметров и связей с процессами саморегуляции личности в условиях болезни дополняет имеющиеся теоретико-методологические представления об адаптации к болезни и расширяет мишени психодиагностической и психокоррекционной деятельности в практической работе клинических психологов. Причем важным представляется именно качественный анализ когнитивных репрезентаций болезни, содержания ее личностного смысла в жизни пациента. 
ЯЛТОНСКИЙ В. М., АБРОСИМОВ И. Н., АНДРУШКЕВИЧ Т. Д., ШАШУРИНА Е. М.

ИССЛЕДОВАНИЕ ПАРАМЕТРОВ ВНУТРЕННЕЙ КАРТИНЫ БОЛЕЗНИ...

РОССИЙСКИЙ ПСИХОЛОГИЧЕСКИЙ ЖУРНАЛ, 2020, Т. 17, № 1, 15-26. doi: 10.21702/rpj.2020.1.2

МЕДИЦИНСКАЯ ПСИХОЛОГИЯ

Выводы:

1. Клиническое течение ревматических болезней зачастую носит нелинейный во времени и мультисистемный по проявлениям характер. Эта специфика обуславливает возрастание уровня неопределенности в условиях болезни, что отражается в диффузной структуре чувственного уровня внутренней картины болезни в обеих группах и в высокой готовности тревожного реагирования в группе пациентов с системной красной волчанкой.

2. Когнитивный и мотивационный уровни внутренней картины болезни пациентов с ревматоидным артритом, в сравнении с пациентами с системной красной волчанкой, отличает недостаточное понимание механизмов и сроков течения имеющегося у них заболевания, а также использование сфокусированных на эмоциях, но не на решении актуальных проблем, копинг-стратегий.

3. Установленные корреляции между изучаемыми параметрами указывают на связь восприятия своей болезни с ее диффузным телесным образом и избегающего копинга с тревожным реагированием у пациентов с ревматоидным артритом, а в группе пациентов с системной красной волчанкой - на связь специфики восприятия болезни с негативными эмоциональными переживаниями.

\section{Литература}

Абросимов, И. Н. и Ялтонский, В. М. (2018). Выбор копинг-стратегии как фактор психологической адаптации пациента к хроническому соматическому заболеванию. Вестник Омского университета. Серия «Психология», 4, 12-18. doi: 10.25513/2410-6364.2018.4.12-18

Алпысова, А. Р. и Суббота, Ю. В. (2017). Соматические заболевания у медицинских работников. Обзор литературы. Международный журнал прикладных и фундаментальных исследований, 11-1, 37-39. Доступ 24 апреля 2019, источник https://applied-research.ru/ ru/article/view?id $=11926$

Ахмедова, О. С. и Щелкова, О. Ю. (2008). Психологическая диагностика в соматической клинике: особенности адаптации личности к заболеваниям с различной динамикой течения. Вестник Санкт-Петербургского университета. Серия 12. Психология. Социология. Педагогика, 3, 502-510.

Бегун, Д. Н. и Борщук, Е. Л. (2013). Проблемы профилактики ревматических болезней среди взрослого населения оренбургской области. Результаты социологического исследования. Вестник Оренбургского здравоохранения, 1, 17-19.

Березина, Е. Б. (2011). Содержание и структура обыденных представлений о болезнях в молодежной среде (кандидатская диссертация). МГУ им. М. В. Ломоносова, Москва.

Василенко, Т. Д. и Мангушев, Ф. Ю. (2018). Особенности внутреннего телесного опыта при соматоформных расстройствах. Медицинская психология в России, 10(1), 7. doi: 10.24411/2219-8245-2018-11071

Вассерман, Л. И., Чугунов, Д. Н. и Щелкова, О. Ю. (2019). Соотношение субъективных и объективных факторов в процессе формирования внутренней картины болезни и совладающего поведения. Консультативная психология и психотерапия, 27(2), 82-94. doi: 10.17759/срр.2019270206

Воробьева, Л. Д. и Асеева, Е. А. (2017). Значение качества жизни, связанного со здоровьем, у больных системной красной волчанкой и современные инструменты его оценки. Современная ревматология, 11(4), 62-72. doi: 10.14412/1996-7012-2017-4-62-72 
ЯЛТОНСКИЙ В. М., АБРОСИМОВ И. Н., АНДРУШКЕВИЧ Т. Д., ШАШУРИНА Е. М.

ИССЛЕДОВАНИЕ ПАРАМЕТРОВ ВНУТРЕННЕЙ КАРТИНЫ БОЛЕЗНИ...

РосСИЙСКИЙ пСИХОЛОГИЧЕСКИЙ ЖУРнАл, 2020, Т. 17, № 1, 15-26. doi: 10.21702/rpj.2020.1.2

МЕДИЦИНСКАЯ ПСИХОЛОГИЯ

Воробьева, Л. Д., Асеева, Е. А., Соловьев, С. К., Койлубаева, Г. М. и Глухова, С. И. (2019). Влияние терапии на качество жизни, связанное со здоровьем, у пациентов с системной красной волчанкой (по данным регистра РЕНЕССАНС). Научно-практическая ревматология, 57(4), 421-425. doi: 10.14412/1995-4484-2019-421-425

Грехов, Р. А., Сулейманова, Г. П., Харченко, С. А., Папков, А. Ю., Рудыкина, О. А., Бондаренко, Е. А., ... Зборовская, И. А. (2009). Психосоматические основы тревожно-депрессивных нарушений у больных ревматическими заболеваниями. Военно-медицинский журнал, 330(8), 69-72.

Кудряшова, В. Ю., Сарайкин, Д. М. и Иванов, М.В.(2017). Копинг-стратегии и саморегуляция поведения у больных шизофренией и аффективными расстройствами. Обозрение психиатрии и медицинской психологии, 2, 33-39.

Кулик, М. С., Барзилович, В. Д. и Минченко, А. (2012). Ревматоидный артрит. Особенности этиопатогенеза. Украинский научно-медицинский молодежный журнал, 1, 71-74.

Лисицына, Т. А., Вельтищев, Д. Ю., Серавина, О. Ф., Ковалевская, О. Б., Старовойтова, М. Н., Десинова, О. В., ... Насонов, Е. Л. (2018). Сравнительный анализ расстройств тревожно-депрессивного спектра у больных ревматическими заболеваниями. Терапевтический архив, 90(5), 30-37. doi: 10.26442/terarkh201890530-37

Лифинцева, А. А., Деркач, Т. Д. и Штолде, Н. (2018). Феномен неопределенности как субъективный опыт пациента в ситуации болезни. Клиническая и специальная психология, 7(1), 1-12. doi: 10.17759/cpse.2018070101

Марченко, А. С., Серавина, О. Ф., Ковалевская, О. Б., Вельтищев, Д. Ю. и Лисицына, Т. А. (2009). Аффективно-стрессовая модель депрессии: практическое внедрение в ревматологической практике. Психиатрия и психофармакотерапия, 11(5), 17-21.

Месникова, И. Л. и Сенюта, Е. В. (2016). Состояние адаптации и качество жизни пациентов с остеоартритом и ревматоидным артритом. Военная медицина, 1(38), 42-47.

Незнанов, Н. Г., Коцюбинский, А. П. и Мазо, Г. Э. (2018). Биопсихосоциальная концепция психических расстройств как основа холистического диагностического подхода. Часть II. Социальная и клиническая психиатрия, 28(4), 47-53.

Рассказова, Е. И. (2012). Саморегуляция в психологии здоровья и клинической психологии. Вопросы психологии , 1, 75-82.

Соловьев, С. К., Меснянкина, А. А. и Асеева, Е. А. (2019). Перспективы анти-BLyS-терапии системной красной волчанки. Медицинский совет, 9, 92-95. doi: 10.21518/2079-701X-2019-9-92-95

Тарабрина, Н. В. (2001). Практикум по психологии посттравматического стресса. СанктПетербург: Питер.

Хамитов, Е. А., Хисметова, 3. А., Горемыкина, М. В., Танышева, Г. А. и Котляр, А. (2019). Факторы, влияющие на приверженность к терапии у пациентов с системной красной волчанкой. Наука и здравоохранение, 21(5), 103-109.

Цветкова, И. В. (2012). Проблема психологического изучения внутренней картины здоровья. Психологические исследования, 1(21). Доступ 21 декабря 2019, источник http://psystudy. ru/index.php/num/2012n1-21/612

Ялтонский, В. М. и Абросимов, И. Н. (2011). Субъективное восприятие болезни как угрозы и способы её преодоления у больных муковисцидозом. В Клиническая психология в здравоохранении и образовании (с. 97-101). Москва: Московский государственный медико-стоматологический университет. 
ЯЛТОНСКИЙ В. М., АБРОСИМОВ И. Н., АНДРУШКЕВИЧ Т. Д., ШАШУРИНА Е. М.

ИССЛЕДОВАНИЕ ПАРАМЕТРОВ ВНУТРЕННЕЙ КАРТИНЫ БОЛЕЗНИ...

РОССИЙСКИЙ ПСИХОЛОГИЧЕСКИЙ ЖУРНАЛ, 2020, Т. 17, № 1, 15-26. doi: 10.21702/rpj.2020.1.2

МЕДИЦИНСКАЯ ПСИХОЛОГИЯ

Ялтонский, В. М. и Абросимов, И.Н.(2014). Совладающее с болезнью поведение взрослых с муковисцидозом. Национальный психологический журнал, 3(15), 60-65. doi: 10.11621/ nрj.2014.0307

Ялтонский, В. М., Московченко, Д. В., Сирота, Н. А. и Ялтонская, А. В. (2017). Психометрические характеристики модифицированного опросника восприятия болезни: апробация на больных раком молочной железы и ишемической болезнью сердца. Клиническая и специальная психология, 6(2), 158-174. doi: 10.17759/cpse.2017060212

Brijs, J., Arat, S., Westhovens, R., Lenaerts, J. L., \& De Langhe, E. (2019). Treatment adherence in systemic sclerosis: A cross-sectional study. Musculoskeletal Care, 17(1), 44-53. doi: 10.1002/ msc. 1363

Mc Hugh, R., Mc Feeters, D., Boyda, D., \& O'Neill, S. (2016). Coping styles in adults with cystic fibrosis: Implications for emotional and social quality of life. Psychology, Health \& Medicine, 21(1), 102-112. doi: 10.1080/13548506.2015.1020317

Karademas, E. C., Bakouli, A., Bastounis, A., Kallergi, F., Tamtami, P., \& Theofilou, M. (2008). Illness perceptions, illness-related problems, subjective health and the role of perceived primal threat: Preliminary findings. Journal of Health Psychology, 13(8), 1021-1029. doi: $10.1177 / 1359105308097967$

Li, X., He, L., Wang, J., \& Wang, M. (2019). Illness uncertainty, social support, and coping mode in hospitalized patients with systemic lupus erythematosus in a hospital in Shaanxi, China. PLOS One, 14(2), e0211313. doi: 10.1371/journal.pone.0211313

Nowicka-Sauer, K., Hajduk, A., Kujawska-Danecka, H., Banaszkiewicz, D., Smoleńska, Ż., Czuszyńska, Z., \& Siebert, J. (2018). Illness perception is significantly determined by depression and anxiety in systemic lupus erythematosus. Lupus, 27(3), 454-460. doi: 10.1177/0961203317751858

Pakhale, S., Baron, J., Armstrong, M., Tasca, G., Gaudet, E., Aaron, S., ... Balfour, L. (2015). A crosssectional study of the psychological needs of adults living with cystic fibrosis. PLOS ONE, 10(6), e0127944. doi: 10.1371/journal.pone.0127944

Ulus, Y., Tander, B., Akyol, Y., Terzi, Y., Zahiroğlu, Y., Sarisoy, G., ... Kuru, Ö. (2017). Are illness perceptions associated with disease activity or psychological well-being in rheumatoid arthritis? A study with the evidence of confirmatory factor analysis. Archives of Rheumatology, 32(4), 315-324.

Yen, E. Y., \& Singh, R. R. (2018). Lupus - an unrecognized leading cause of death in young women: A population-based study using nationwide death certificates, 2000-2015. Arthritis \& Rheumatology, 70(8), 1251-1255. doi: 10.1002/art.40512

Конфликт интересов отсутствует 